\title{
Absorption and Emission Spectrum of $\mathrm{CaF}_{2}: \mathrm{U}^{3+}$ from 2.1 to 2.5 Microns*
}

\author{
Robert E. Meredith and Joe A. Jenney \\ Institute of Science and Technology, The University of Michigan, Ann Arbor, Michigan
}

(Received 15 July 1963)

\begin{abstract}
The emission and absorption of $\mathrm{CaF}_{2}: \mathrm{U}^{3+}$ has been scanned at $77^{\circ}$ and $4.2^{\circ} \mathrm{K}$ and linewidths have been measured. The spectrum is interpreted as arising from ions perturbed by a weak tetragonal crystal field. Preliminary results of the Zeeman effect on the narrowest lines are presented.
\end{abstract}

\section{INTRODUCTION}

$\mathbf{T}$ $\mathrm{HE}$ discovery ${ }^{1,2}$ of $\mathrm{CaF}_{2}: \mathrm{U}^{3+}$ as a laser material has caused an increased interest in the spectra of uranium ions in alkaline-earth fluoride lattices. It has been established $d^{3,4}$ that tetravalent uranium ions occupy sites of trigonal symmetry in $\mathrm{CaF}_{2}$, and that trivalent uranium can occupy both cubic and tetra-

TABLE I. Ahsorption of $\mathrm{CaF}_{2}: \mathrm{U}^{3+}$ at $4.2^{\circ} \mathrm{K}$.

\begin{tabular}{cccc}
\hline \multicolumn{2}{c}{0.1 mole \% } & \multicolumn{2}{c}{0.05 mole \% } \\
$\begin{array}{c}\text { Frequency } \\
\left(\mathrm{cm}^{-1}\right)\end{array}$ & $\begin{array}{c}\text { Half-width } \\
\left(\mathrm{cm}^{-1}\right)\end{array}$ & $\begin{array}{c}\text { Frequency } \\
\left(\mathrm{cm}^{-1}\right)\end{array}$ & $\begin{array}{c}\text { Half-width } \\
\left(\mathrm{cm}^{-1}\right)\end{array}$ \\
\hline 4707.6 & Broad & 4702 & Broad \\
4672.5 & Broad & 4669 & Broad \\
4523.5 & 1.3 & 4511.2 & 2.9 \\
4512.9 & 3.9 & 4495.7 & 0.363 \\
4498.2 & 0.44 & 4468.2 & 0.40 \\
4469.0 & 1.31 & 4450.8 & 0.71 \\
4450.9 & 0.86 & 4434.8 & 0.57 \\
4435.3 & 0.95 & 4432.6 & 0.51 \\
4433.4 & 0.66 & & \\
4431.9 & 0.36 & & \\
4430.3 & 0.29 & & \\
\hline \hline
\end{tabular}

gonal sites. Moreover, it has been shown that the absorption of uranium ions in $\mathrm{CaF}_{2}$ in the $4500 \mathrm{~cm}^{-1}$ region are due to trivalent ions rather than to tetravalent. ${ }^{4}$

$\mathrm{U}^{3+}$ has a $5 f^{3}$ configuration and it is well known that such ions show a spin-orbit coupling that is large compared to ordinary crystalline electric fields. The

\footnotetext{
* This work was conducted by Project MICHIGAN under Department of the Army Contract Da-36-039-78801 administered by the U.S. Army Electronics Command.

${ }_{1}$ P. P. Sorokin and M. J. Stevenson, Phys. Rev. Letters 5, $557(1960)$.

2 P. P. Sorokin and M. J. Stevenson, Advances in Quantum Electronics (Columbia University Press, New York, 1961), pp. 65-76.

${ }^{3}$ G. D. Boyd, R. J. Collins, S. P. S. Porto, and A. Yariv, Phys. Rev. Letters 8, 269 (1962).

${ }^{4}$ R. S. Title, P. P. Sorokin, M. J. Stevenson, G. D. Pettit, J. E. Scardefield, and J. R. Lankard, Phys. Rev. 128, 62 (1962).
}

lowest frequency transitions in the infrared due to $\mathrm{U}^{3+}$ in $\mathrm{CaF}_{2}$ should therefore arise from a splitting of the ${ }^{4} I_{9 / 2}$ and ${ }^{4} I_{11 / 2}$ levels due to the local crystal field at the $\mathrm{U}^{3+}$ site. In the case of $\mathrm{U}^{3+}$ in tetragonal sites, the ground ${ }^{4} I_{9 / 2}$ level splits into five doublets, and the ${ }^{4} I_{11 / 2}$ level splits into six doublets, implying that six absorption transitions should be observed in the near infrared. The purpose of this paper is to present fairly high resolution spectra of $\mathrm{CaF}_{2}: \mathrm{U}^{3+}$ at low temperatures which are easily interpreted as arising from ions in the tetragonal sites. A detailed investigation of the Zeeman

\begin{tabular}{cc} 
TABLE II. Emission of $\mathrm{CaF}_{2}: \mathrm{U}^{3+}$ at $4.2^{\circ} \mathrm{K}$. \\
\hline \multicolumn{2}{c}{0.05 mole $\%$} \\
$\begin{array}{c}\text { Frequency } \\
\left(\mathrm{cm}^{-1}\right)\end{array}$ & $\begin{array}{c}\text { Half-width } \\
\left(\mathrm{cm}^{-1}\right)\end{array}$ \\
\hline 4496.2 & 2.27 \\
4452.4 & 1.3 \\
4444.9 & 1.8 \\
4439.0 & 1.8 \\
4432.3 & 1.95 \\
4269.1 & 1.32 \\
4240.4 & 1.2 \\
4100 & Broad \\
3970 & Broad \\
\hline
\end{tabular}

effect of these crystals has begun, and preliminary results are presented.

\section{EXPERIMENTAL PROCEDURE}

All spectra were taken with a 1 -m-focal-length infrared spectrometer utilizing a $6-\times 8$-in. 180 -line $/ \mathrm{mm}$ grating in a Pfund-type mount. The spectrometer was built at the University of Michigan in 1930 by Hardy, primarily for use in the medium infrared. It has been found that the resolution of the instrument is limited in the $2-\mu$ region by the quality and design of the slits. All absorption spectra were obtained with $0.2 \mathrm{~cm}^{-1}$ spectral slitwidths using a $500-\mathrm{W}$ tungsten lamp as a source and an O-type lead sulfide detector cooled to dry-ice temperature. This resolution was measured by 

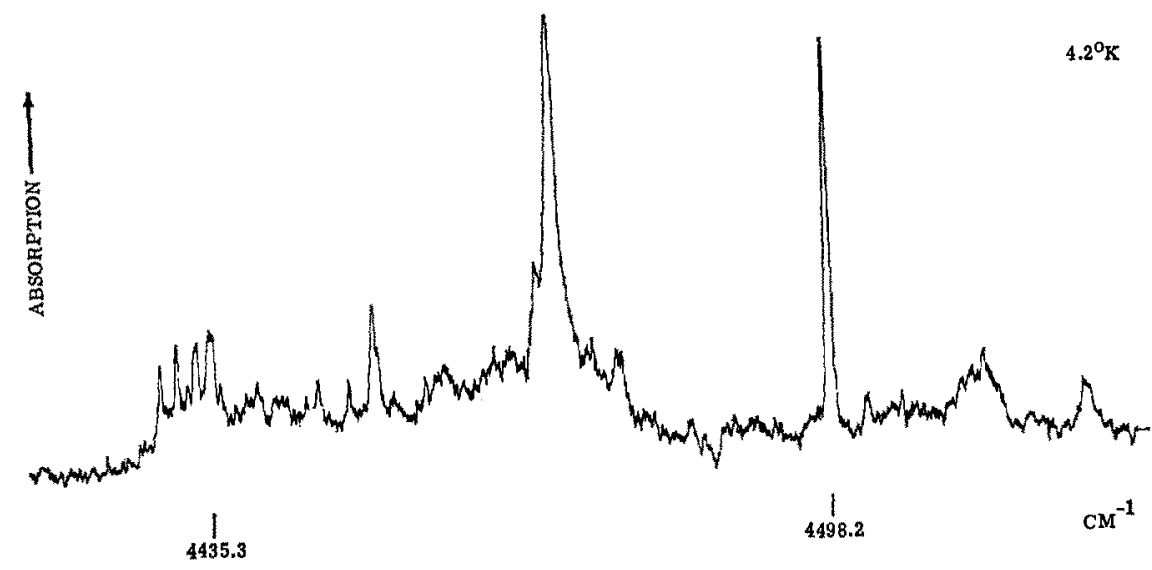

总

总


Fig. 1. Absorption spectrum of 0.1 . mole $\% \mathrm{CaF}_{2}: \mathrm{U}^{3+}$ at $4.2^{\circ} \mathrm{K}$. 
scanning the carbon monoxide overtone at 2.4- $\mu$. Since the linewidths of the $\mathrm{CaF}_{2}: \mathrm{U}^{3+}$ were all considerably larger than this, it is believed that in most cases natural linewidths were being observed. It is possible, of course, that the width of the narrowest line is actually slightly less than the measured 0.363 $\mathrm{cm}^{-1}$.

The emission spectra were taken with resolution no better than $0.5 \mathrm{~cm}^{-1}$ since the lines were so weak the slits had to be opened somewhat. The noticeably broader lines in emission at liquid helium are, however, attributed to an unavoidable heating of the samples caused by the pump radiation.

\section{EXPERIMENTAL RESULTS AND INTERPRETATION}

Absorption and emission spectra of $\mathrm{CaF}_{2}: \mathrm{U}^{3+}$ at both liquid-nitrogen and liquid-helium temperatures

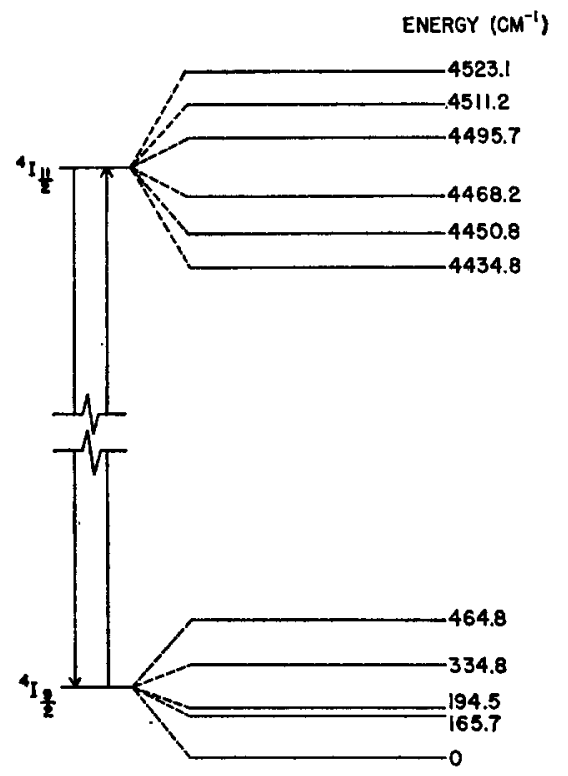

FIG. 4. Splitting of the ${ }^{4} I_{11 / 2}$ and ${ }^{4} I_{9 / 2}$ levels as deduced from the absorption and emission spectra.

have been taken. Samples containing both 0.1 and 0.05 mole $\% \mathrm{U}^{3+}$ in $\mathrm{CaF}_{2}$ have been investigated, the former having a very large percentage of the $\mathrm{U}^{3+}$ in tetragonal sites. Some of the scans are shown in Figs. 1 to 3. The positions of the lines are tabulated in Tables I and II, along with their half-widths. It has been found that the spectrum of the 0.05 mole \% samples were almost identical with that of the darker except for relative intensities in some of the weaker lines.

Figure 4 shows the energy-level diagram deduced from the data. If the splitting of the lowest frequency absorption at liquid helium is ignored, there are six transitions from 4430 to $4530 \mathrm{~cm}^{-1}$ which immediately present themselves as transitions from the ground state to the ${ }^{4} I_{11 / 2}$ levels. The absorptions at 4672 and 4707 $\mathrm{cm}^{-1}$ are much broader at $77^{\circ} \mathrm{K}$ than the others, and they narrow down only slightly when cooled down
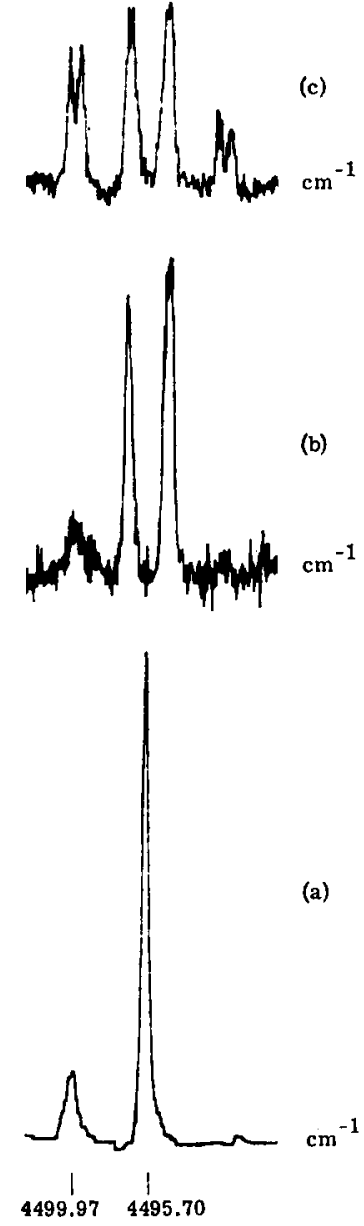

FIG. 5. Zeeman splitting of the 4495.70- $\mathrm{cm}^{-1}$ absorption: (a) unsplit line; (b) splitting using radiation polarized parallel to the magnetic field; (c) splitting using radiation polarized perpendicular to the magnetic field.

TABIE III. (a) Line positions of the Zeeman spectrum of the $4495.7 \mathrm{~cm}^{-1}$ absorption in 0.05 -mole $\% \mathrm{CaF}_{2} \mathrm{U}^{3+}$; (b) line positions of the Zeeman spectrum of the 4498.2-cm-1 absorption in the $0.1-$ mole $\% \mathrm{CaF}_{2}: \mathrm{U}^{3+}$. In both (a) and (b) the magnetic field is $21000 \mathrm{G}$.

(a)

(b)

\begin{tabular}{cccc}
$\begin{array}{c}\text { Frequency } \\
\left(\mathrm{cm}^{-1}\right)\end{array}$ & $\begin{array}{c}\text { Polari- } \\
\text { zation }\end{array}$ & $\begin{array}{c}\text { Frequency } \\
\left(\mathrm{cm}^{-1}\right)\end{array}$ & $\begin{array}{c}\text { Polari- } \\
\text { zation }\end{array}$ \\
\hline 4492.02 & $\mathbf{E} \perp \mathbf{H}$ & 4494.48 & $\mathbf{E} \perp \mathbf{H}$ \\
4492.76 & $\mathbf{E} \perp \mathbf{H}$ & 4497.46 & $\mathbf{E} \perp \mathbf{H}$ \\
4494.55 & $\mathbf{E} \perp \mathbf{H}$ & 4498.94 & $\mathbf{E} \perp \mathbf{H}$ \\
4496.85 & $\mathbf{E} \perp \mathbf{H}$ & 4501.92 & $\mathbf{E} \perp \mathbf{H}$ \\
4498.64 & $\mathbf{E} \perp \mathbf{H}$ & 4497.13 & $\mathbf{E} \| \mathbf{H}$ \\
4499.58 & $\mathbf{E} \perp \mathbf{H}$ & 4499.27 & $\mathbf{E} \| \mathbf{H}$ \\
4494.46 & $\mathbf{E} \| \mathbf{H}$ & & \\
4496.94 & $\mathbf{E} \| \mathbf{H}$ & & \\
\hline
\end{tabular}




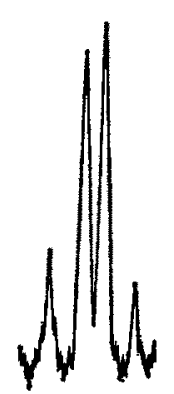

(c)

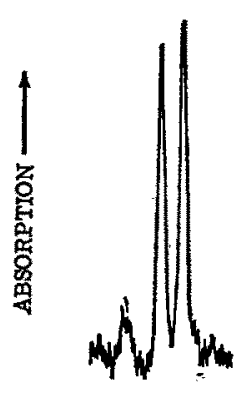

(b)

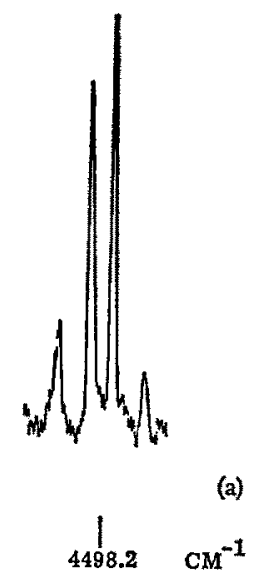

Fis. 6. Zeeman splitting of the $4498.2-\mathrm{cm}^{-1}$ absorption: (a) splitting using unpolarized radiation; (b) splitting using radiation polarized parallel to the magnetic field; (c) splitting using radiation polarized perpendicular to the magnetic field.

to $4.2^{\circ} \mathrm{K}$. The center of this high-frequency absorption is about $257 \mathrm{~cm}^{-1}$ away from the 4435.3 line, so it is natural to assign these transitions to combinations of the electronic transitions from the ground state with vibrational quanta. Similar assignments have been made by many other workers investigating impurities in calcium fluoride lattices.

Figures 2 and 3 offer strong support of the energylevel diagram of Fig. 4. The emission scan at liquidhelium temperature shows a marked change in relative intensity of the lines when compared with the liquidnitrogen scan. This is what should be expected if the lowest-lying ${ }^{4} I_{11 / 2}$ level is actually at $4435.3 \mathrm{~cm}^{-1}$. At liquid helium, no emission was observed at frequencies greater than $4500 \mathrm{~cm}^{-1}$.

It can be seen from Fig. 3 that the emission corresponding to the $4435 \mathrm{~cm}^{-1}$ and the $4450.8 \mathrm{~cm}^{-1}$ absorptions have split at liquid-helium temperature. The cause of these splittings is not known, but it is possible that these are concentration effects.

Due to the presence of fairly strong atmospheric $\mathrm{H}_{2} \mathrm{O}$ bands below $4200 \mathrm{~cm}^{-1}$, it was not possible to measure the half-widths of the lowest-lying emission transitions, the positions of the corresponding levels of the ${ }^{4} I_{9 / 2}$ manifold are of doubtful accuracy.

Although this interpretation of the observed spectra is quite reasonable, it cannot be said that the assignments given here are proved beyond a doubt. Indeed, the spectra of trivalent ions occupying tetragonal sites in $\mathrm{CaF}_{2}$ crystals have been interpreted recently using only cubic crystal-field parameters. ${ }^{5,6}$ An investigation of the Zeeman effect of these samples is therefore in progress in order to measure $g$ values and to confirm the above assignments. The Zeeman pattern arising from the narrowest line of both the 0.05 and 0.01 mole $\%$ samples are shown in Figs. 5 and 6, and the splittings are tabulated in Table III. The interpretation of the Zeeman patterns is complicated by the possibility that the $\mathrm{U}^{3+}$ can occupy magnetically inequivalent sites, and can therefore give more lines than one would expect from transitions between doublets. Also, most of the lines in both the absorption and emission spectra are too broad even at low temperatures to resolve all the detail of the Zeeman patterns, and it is hoped that the use of higher quality samples will remove this difficulty.

${ }^{5}$ J. P. Wittke, A. J. Kiss, R. C. Duncan, and J. J. McCormick, Proc. IRE 51, 56 (1963).

${ }^{6}$ Z. J. Kiss, J. Chem. Phys. 38, 1478 (1963). 